Research Article

\title{
Three-Dimensional Stochastic Seepage Field Analysis of Multimedia Embankment
}

\author{
Xiaoming Zhao $\mathbb{D}^{1,2}$ Shiyu Shang $\mathbb{D}^{1},{ }^{1}$ Yuanlin Yang $\mathbb{D}^{1},{ }^{1}$ and Mingming $\mathrm{Hu} \mathbb{D}^{1}$ \\ ${ }^{1}$ School of Civil Engineering, Xuchang University, Xuchang, Henan 461000, China \\ ${ }^{2}$ The Scientific Research Innovation Team of Xuchang University, Xuchang, China \\ Correspondence should be addressed to Xiaoming Zhao; zhaoxiaoming@xcu.edu.cn
}

Received 12 November 2021; Revised 26 November 2021; Accepted 27 November 2021; Published 15 December 2021

Academic Editor: Bingxiang Yuan

Copyright (c) 2021 Xiaoming Zhao et al. This is an open access article distributed under the Creative Commons Attribution License, which permits unrestricted use, distribution, and reproduction in any medium, provided the original work is properly cited.

The soil hydraulic conductivity of an embankment has strong spatial variability due to the spatiotemporal variation, both natural and artificial. The strong randomness of the hydraulic conductivity can be expressed by the coefficient of variation (COV) and the fluctuation scale $\theta$. Moreover, different coefficients of variation and fluctuation scales correspond to different random field structures. To study the characteristics of the three-dimensional stochastic seepage field in an embankment under different COVs and fluctuation scales, we generate a three-dimensional random field of the hydraulic conductivity of multimedia embankment based on the local average subdivision technique. In particular, a calculation method for a three-dimensional random seepage field based on the Monte Carlo method combined with a three-dimensional multimedia random field and a deterministic analysis is proposed. The results showed that after three thousand realizations and considering the randomness of the hydraulic conductivity, the position of the free surface of each section in the embankment differed. The mean value of the total head decreased when the COV increased. Furthermore, when the COV was small, the change in the total head with anisotropy ratio was not evident, while the COV was large. The mean value of the total head increased with the anisotropy ratio. When the anisotropy ratio increased, the mean value of the standard deviation of the total head increased first and then decreased.

\section{Introduction}

Research problems related to geotechnical engineering present uncertainties and randomness. For instance, due to the spatiotemporal variation, both natural and artificial, the soil hydraulic conductivity of an embankment has strong spatial variability. In this regard, the study of random field theory appeared earlier in the mathematics and physics fields. From these fields, a particular fast Fourier transform algorithm proposed by Cooley and Tukey has been used to generate random fields [1]. Moreover, Matheron proposed the Turning Bands Method (TBM) to generate a random field [2], and the accuracy of the random field generated by the TBM method was closely related to the number of lines. Moreover, Mantoglou and Wilson developed the TBM random field theory [3] and used this method to simulate various random fields. Vanmarcke [4-6] proposed the local average random field theory in which the local mean value and standard deviation of random variables represented the variation characteristics of the random field in this space. Fenton proposed a random field generation method based on the local average subdivision (LAS) technique $[7,8]$. For one-dimensional or two-dimensional random variables, given the probability density function and statistical parameters, such as mean, standard deviation, and fluctuation scale, the random field comprising regular quadrilateral elements could be generated in a rectangular region in onedimensional or two-dimensional space. This random field generation technique has the advantages of fast convergence and low theoretical error.

Fenton systematically introduces the basic theory of random field and common random field generation methods. It is found that most errors are related to the accuracy of covariance [9-11]. Zhu et al. studied the reliability of undrained slope by using the stochastic finite element method. The research focuses on the spatial 
fluctuation scale in the worst case, that is, the fluctuation scale when the slope failure probability reaches its maximum value. The results show that the worst case is most likely to occur when the average safety factor is low or the coefficient of variation is high [12]. Based on the random field of soil hydraulic conductivity, taking the hydraulic conductivity as a spatial random field variable subject to lognormal distribution, the free surface seepage of a gravity dam is analyzed by the Monte Carlo method [13]. Then, the mean and variance of the total velocity in the gravity dam are obtained. Ahmed [14, 15] considered that the probability density function of hydraulic conductivity obeys lognormal distribution, and the random method is used to analyze the free surface seepage of the gravity dam. The results show that the flow rate in random analysis is smaller than that in deterministic analysis, and the height of free surface in random analysis is lower than that in deterministic analysis. The flow rate and hydraulic gradient have a certain correlation with the COV and fluctuation scale [16, 17]. Literature [18-21] also studied the stable seepage with a random method and obtained similar conclusions. Soil cracking will affect seepage and evaporation [22-25]; then, the stress field and displacement field of other engineering such as pile foundation and slope will be affected [26-31].

The spatial variability of soil hydraulic conductivity changes the distribution of streamline and equipotential line of the seepage field. Compared with deterministic analysis, the elevation of the overflow point, total head, seepage force, and flow have changed significantly, which brings additional risks. In order to improve the accuracy in predicting the risk probability of seepage instability, we need to improve the understanding of the random seepage field of the embankment. In this study, considering the strong variability of embankment soil hydraulic conductivity, a three-dimensional multimedia random field is generated based on the local average subdivision technique, and a calculation method for a three-dimensional random seepage field of an embankment based on the Monte Carlo method combined with a three-dimensional multimedia random field and a deterministic seepage field analysis method is proposed.

\section{The Random Field Model of Hydraulic Conductivity}

When obtaining random seepage fields, the probability density function of the soil hydraulic conductivity is often considered that follows the lognormal distribution [32-36]. Assume that the mean value of a random field of hydraulic conductivity is $\mu_{k}$ and the variance is $\sigma_{k}^{2}$; thus, $\ln k$ obeys the normal distribution with a mean value of $\mu_{\ln k}$ and a variance of $\sigma_{\ln k}^{2}$, as shown in the following equation:

$$
\begin{aligned}
& \sigma_{\ln k}^{2}=\ln \left(1+\frac{\sigma_{k}^{2}}{\mu_{k}^{2}}\right) \\
& \mu_{\ln k}=\ln \left(\mu_{k}\right)-\frac{1}{2} \sigma_{\ln k}^{2} .
\end{aligned}
$$

The hydraulic conductivity of the saturated seepage unit can be obtained using the following equation:

$$
k_{i}=\exp \left(\mu_{\ln k}+\sigma_{\ln k} g_{i}\right)
$$

in which $k_{i}$ is the hydraulic conductivity assigned to the $i$ th unit in the random field and $g_{i}$ is the local average of a standard Gaussian random field over the domain of the $i$ th unit.

Considering the characteristics of a Gauss-Markov process, the exponential correlation function is selected, which can be written as follows:

$$
\rho(\tau)=\exp \left(-\frac{2}{\theta}|\tau|\right)
$$

where $\tau$ is the distance between any points in the random field and $\theta$ is the fluctuation scale of variables in the random field. The fluctuation scale is the distance over which points in the random field are significantly correlated.

The three-dimensional multimedia random field model is generated based on the LAS technique. The Monte Carlo stochastic finite element analysis method was used combined with the deterministic finite element analysis method of the seepage field to analyze the seepage problem several times. According to the statistics of the results, the distribution law of the overflow point elevation and the mean and variance of the total water head in the seepage field were obtained. When the three-dimensional random field was discretized, the value of the COV could be set to change from small to large so that the variation law of each response of the seepage field when the COV changes could be reflected in the random analysis. At the same time, in order to reflect the differences between the random field method and the random variable method, different fluctuation scales can be selected to analyze the variation law of response. The distribution law of the overflow point elevation and the mean and variance of the total water head in the seepage field is obtained.

\section{Numerical Calculation Model}

The simplified model of a section of Shijiu Lake embankment, located in Nanjing City, Jiangsu Province, and its section is shown in Figure 1. The model is $36 \mathrm{~m}$ along the embankment axis. Moreover, the embankment foundation is $144 \mathrm{~m}$ wide in the $X$ direction and $24 \mathrm{~m}$ high in the $Z$ direction. The foundation is divided into two layers. The upper layer is a relatively thin, heavy silty soil layer with a thickness of $4 \mathrm{~m}$, and the lower layer is a muddy, silty fine sand layer with a thickness of $20 \mathrm{~m}$. The bottom of the embankment is $54 \mathrm{~m}$ wide, $8 \mathrm{~m}$ high, and $6 \mathrm{~m}$ wide at the top of the embankment. The slopes on both sides are graded according to the slope of $1: 3$. During the mesh generation of the model, considering the influence of calculation accuracy and size effect, the mesh size of the embankment body is determined to be $3 \mathrm{~m} \times 1 \mathrm{~m} \times 3 \mathrm{~m}$ in the $X Y Z$ direction, respectively, foundation 1 is determined to be $3 \mathrm{~m} \times 1 \mathrm{~m} \times 3 \mathrm{~m}$ in the $X Y Z$ direction, respectively, and foundation 2 is determined to be $3 \mathrm{~m} \times 3.33 \mathrm{~m} \times 3 \mathrm{~m}$ in the 


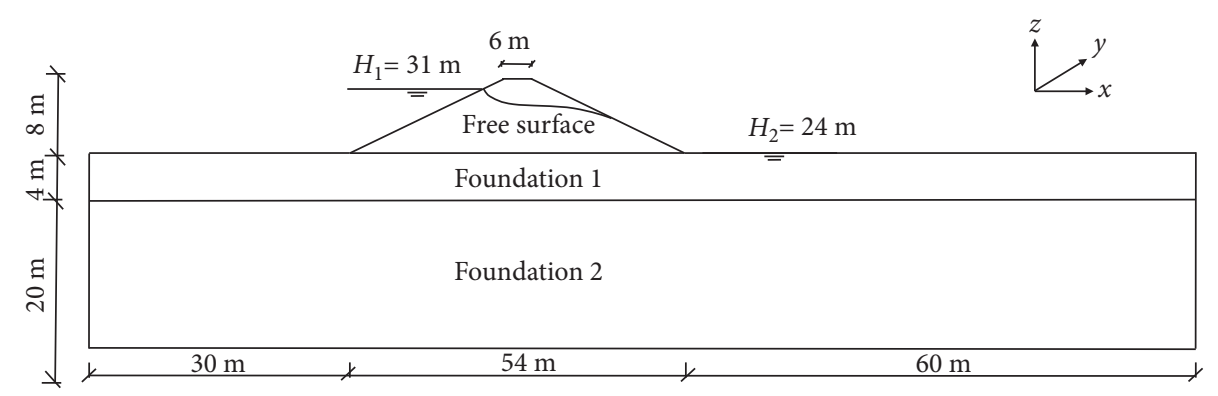

FIgURE 1: Dimension of the embankment.

XYZ direction, respectively. There are 7,488 units and 8,983 nodes in total. In the analysis, considering the randomness of layered soil parameters, the hydraulic conductivity is regarded as a random field variable of anisotropic heterogeneity. The random field of hydraulic conductivity has correlation only in a single soil layer, different soil layers are independent of each other, and their hydraulic conductivity values are independent in the $X Y Z$ direction.

The boundary conditions are as follows: the upstream water level elevation was $31 \mathrm{~m}$, the downstream water level elevation was $24 \mathrm{~m}$, and the bottom of the model and the boundaries on both sides are impervious.

When the water flows through the unit with large hydraulic conductivity, the water head decreases slightly. In contrast, when it flows through the unit with small hydraulic conductivity, the water head decreases greatly. When mapping the hydraulic conductivity random field to the embankment model with equation (2), the hydraulic conductivity of each element in the model is uncertain. A realization refers to a single generation of the hydraulic conductivity random field and the subsequent finite element analysis of the seepage field with ABAQUS. A Monte Carlo process involves a large number of realizations that eventually enable statistical statements to be made about the output quantities of the three-dimensional seepage. After 3,000 independent realizations, the results are statistically analyzed, and the variation law of the three-dimensional random seepage field of the embankment is obtained.

In this study, soil samples are obtained by in situ drilling, and then indoor permeability test is conducted for samples in the same soil layer. Table 1 lists the values of hydraulic conductivity at different parts of the embankment. Based on the three-dimensional multimedia random field model, different COVs and fluctuation scales are selected. For the two soil layers of the embankment foundation, the geometric size as shown in Figure 1 is used to discrete the random field. For the embankment body, a random field is generated in a larger three-dimensional space and finally mapped to the embankment body; then, a complete three-dimensional multimedia random field model of the embankment is established.

The hydraulic conductivity of the random field is statistically analyzed. Figures 2 and 3 show the frequency distribution of the hydraulic conductivity of the embankment body and foundation, respectively. As seen in the figures, both coefficients follow the normal distribution and
TABLE 1: Hydraulic conductivity of the embankment soil.

\begin{tabular}{lccc}
\hline \multirow{2}{*}{ Soil } & \multicolumn{3}{c}{ Mean hydraulic conductivity $(\mathrm{cm} / \mathrm{s})$} \\
& $X$ & $Y$ & $Z$ \\
\hline Embankment body & $3.32 E-06$ & $3.32 E-06$ & $6.64 E-07$ \\
Foundation 1 & $1.81 E-06$ & $1.81 E-06$ & $4.525 E-07$ \\
Foundation 2 & $2.26 E-05$ & $2.26 E-05$ & $1.13 E-05$ \\
\hline
\end{tabular}

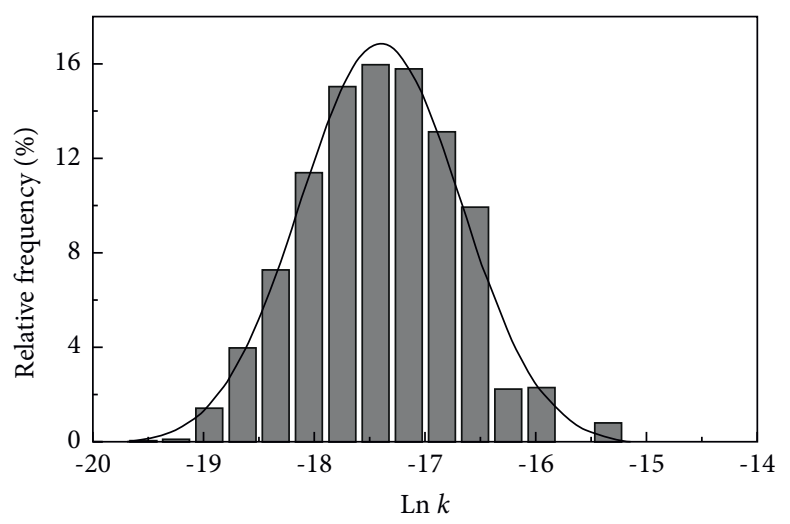

Figure 2: Probability density distribution of the hydraulic conductivity in the embankment body.

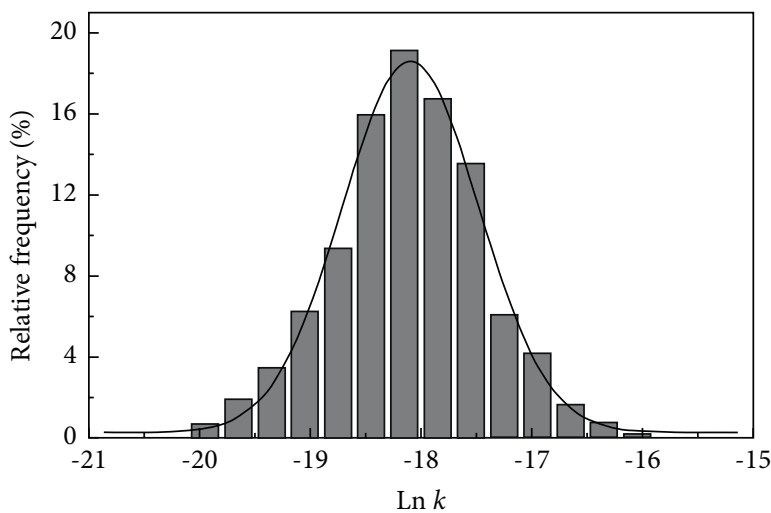

FIgURE 3: Probability density distribution of the hydraulic conductivity in the foundation.

satisfy the spatial distribution characteristics of the hydraulic conductivity. In Figure 2, the value range of the logarithmic hydraulic conductivity is from -15.2 to -19.7 . In Figure 3, 
the value range of the logarithmic hydraulic conductivity is from -15.1 to -20.9 . Obviously, compared with the statistical value of the hydraulic conductivity in the embankment body, the value in the embankment foundation has a wider range. The reason may be that when mapping the hydraulic conductivity of the embankment body, the shape of the embankment is trapezoidal. Elements outside the trapezoidal contour do not participate in random field mapping, and because the upper unit of the embankment body is small, the hydraulic conductivity of the two adjacent units may be the same.

In this study, the hydraulic conductivity is regarded as a random field variable, considering that the embankment has the characteristics of long existence period and obvious layered distribution. Soil parameters have strong variability, so the value range of COV of hydraulic conductivity is large. The hydraulic conductivity is regarded as obeying lognormal distribution, and the COV is taken as 0.1, 0.3, 0.5, 0.7, 1.0, 2.0, and 3.0, respectively. Due to the obvious layered distribution of the embankment in the vertical direction and the long time interval between the formation ages of different soil layers, the correlation of soil parameters between different soil layers is weak.

Generally speaking, the fluctuation scale of hydraulic conductivity in the horizontal plane is much higher than that in the vertical direction. In this study, the vertical fluctuation scale is fixed to $3 \mathrm{~m}$, and the horizontal fluctuation scale is fixed to $3 \mathrm{~m}, 6 \mathrm{~m}, 12 \mathrm{~m}, 24 \mathrm{~m}, 36 \mathrm{~m}$, and $48 \mathrm{~m}$. The anisotropy ratio $\zeta$ can be obtained using the following equation:

$$
\zeta=\frac{\theta_{h}}{\theta_{v}}
$$

where $\theta_{h}$ is the scale of fluctuation in the horizontal plane and $\theta_{v}$ is the scale of fluctuation in the vertical direction.

\section{Results}

4.1. Free Surface. The main purpose of this section is to obtain the variation law of random seepage field response with $\mathrm{COV}$ and fluctuation scale. In order to reflect the influence of COV and fluctuation scale better, it is often changed gradually from small to large in the analysis, and then the curve of random seepage field response with it is obtained. In embankment engineering, the COV and fluctuation scale of different soil layers in a section are certain values, which can be determined by the combination method of experiment and numerical analysis. Based on the results of stochastic finite element analysis of embankment, the mean and standard deviation of free surface position and total head are statistically analyzed, and their distribution laws under different COVs and fluctuation scale combinations are obtained.

Figure 4 shows the free surface calculated in a single time when the COV was 0.3 , the vertical fluctuation scale was $3 \mathrm{~m}$, and the horizontal fluctuation scale was $6 \mathrm{~m}$. Moreover, the figure also shows that, due to the spatial variability of the hydraulic conductivity, the overflow point is not a straight line along the embankment axis. Instead, the overflow point

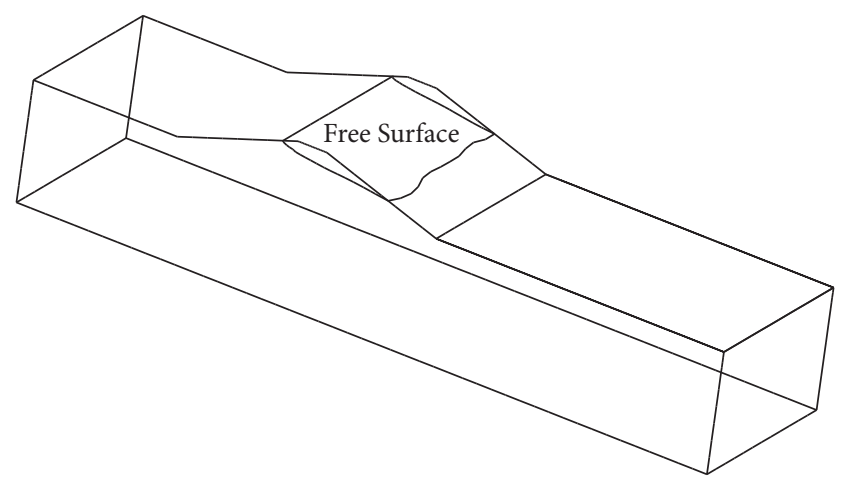

Figure 4: Free surface of three-dimensional random seepage field.

fluctuates up and down, similarly to the actual observation. Furthermore, at different embankment sections, the distribution of free surface and the elevation of the overflow point are different. Therefore, when analyzing the seepage stability of the embankment, considering the spatial variability of hydraulic conductivity reflected the actual situation better. The results obtained are sounded. Moreover, they provide novel insights for engineering practice purposes.

4.2. Random Characteristics of the Total Head. Figure 5 shows that the contour map of the standard deviation of the total head is unevenly distributed, mainly due to the small hydraulic conductivity of the embankment Foundation 1 and the large change of the total head in this soil layer. The slope of the curve varies at the boundary of different soil layers, which agree with the general law of seepage. From the upstream slope to downstream slope, the contour map of the head standard deviation has experienced a process from small to large and then from large to small. The minimum value appears near the upstream slope and downstream slope, and the maximum value appears in the middle of the embankment. The author believes that the reason for this distribution law is that, at the beginning of the analysis, fixed boundary conditions on both sides of the embankment should be given, respectively, that is, at the upstream and downstream boundaries, the standard deviation of the water head is 0 . Some studies have obtained similar results under different COVs and fluctuation scales in the stochastic finite element analysis of pressurized seepage $[37,38]$. In conclusion, considering the influence of random factors, the standard deviation of the water head reaches the maximum value near the embankment center and gradually decreases to both sides of the model. On the surface of the model, the standard deviation is 0 .

In practice, the distribution of the water head in the embankment is the key point to solve other problems. The water head distribution directly affects the distribution of hydraulic gradient and flow rate at each section. Due to the importance of water head distribution, this section analyzes the influence of different COVs and fluctuation scales on water head.

Figure 6 shows the relationship between the mean value of the total head and the COV of the hydraulic conductivity 


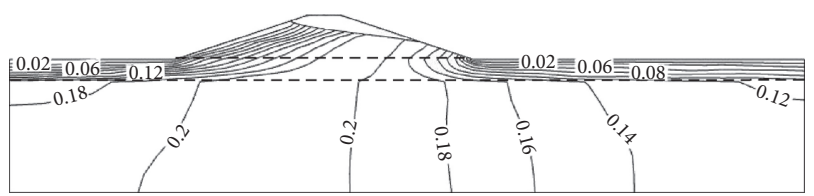

FIGURE 5: Contour map of the standard deviation of the total head.

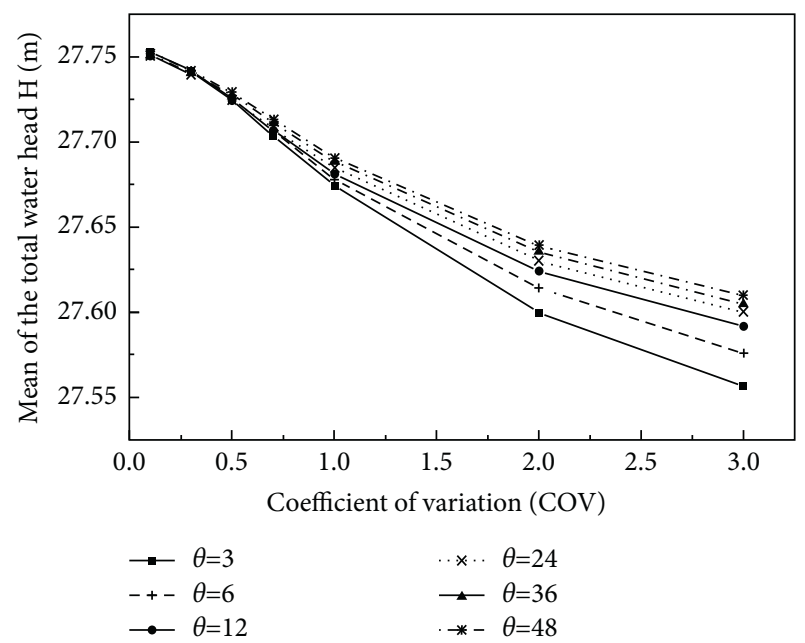

Figure 6: Mean of the total head versus $\mathrm{COV}$ of the hydraulic conductivity.

at each node in the model. The results indicate that the gradual increase in the COV reduces the mean value of node total head shows. When cov $\leq 0.3$, the curve slope is relatively small, and the mean value of the total head decreases slowly; when $0.3<\operatorname{cov} \leq 2$, the slope of the curve is large, and accordingly, the reduction rate of the mean head value is large; when cov $>2$, the slope of the curve decreases gradually. Similarly, the rate of reduction of the mean value of the total head also decreases gradually. When the mean value of the total head is large, the overall head distribution in the model is at a high level, which means that when the average value of the node head is high, the overflow point will also be at a higher position and when the mean value of the node head is small, the overflow point will also appear at the lower position on downstream slope.

Figure 7 shows the relationship between the mean value of the total head and the anisotropy ratio of the random field at each node in the model. When the COV is small, the mean value of the total head hardly changes with the increase in the anisotropy ratio. When the COV is large, the value increases notably with the increase in the anisotropy ratio. Moreover, when $1 \leq \zeta \leq 4$, the mean value of the total head increases rapidly, and when $\zeta>4$, the growth rate of $\mathrm{H}$ decreases significantly. In general, the curve shape is similar to the power function form of the exponent in the $(0,1)$ interval, implying that when the anisotropy ratio reaches a certain degree, obtaining the accurate value of the horizontal fluctuation scale for calculation is not required, and the approximate solution of the relevant problem can be obtained for $\zeta=\infty$. Because the average head distribution can reflect the distribution law of the overflow point elevation to

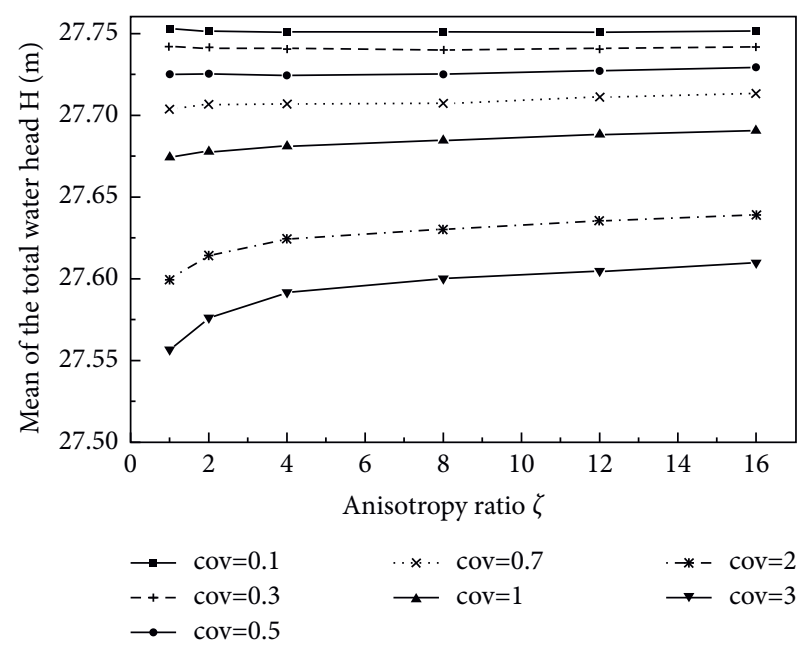

Figure 7: Mean of the total head versus anisotropy ratio of hydraulic conductivity.

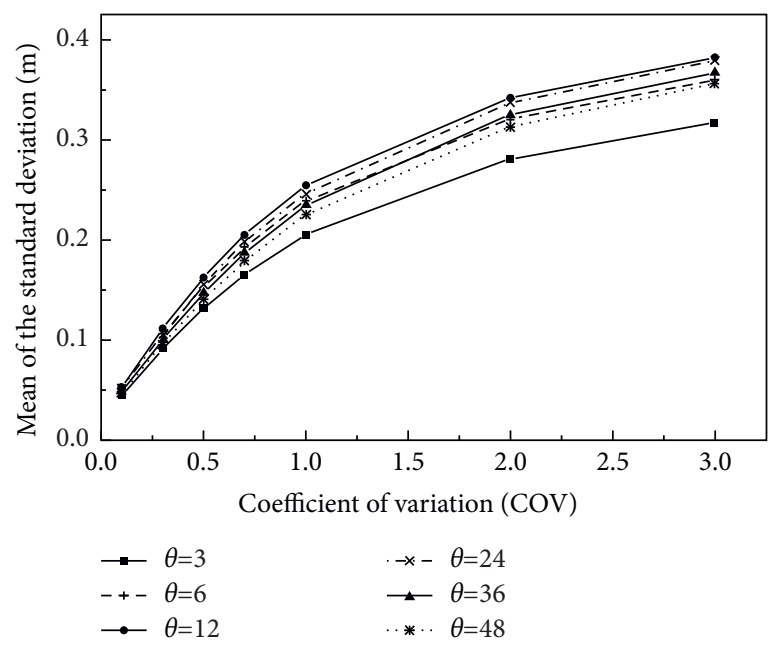

FIGURE 8: Mean of the total head standard deviation versus COV of the hydraulic conductivity.

a certain extent, it can be concluded that when the COV is small, the overflow point elevation changes little with the increase in the anisotropy ratio of the random field and when the COV is large, the elevation of the overflow point changes obviously with the change in anisotropy ratio, and the elevation increase rate appears first fast and then slow.

Figure 8 shows the mean value variation curve of the standard deviation of the total head with the COV of the hydraulic conductivity. The figure shows that the mean value of the standard deviation of the total head increases with an increase in the COV of the hydraulic conductivity. Furthermore, the curve slope decreases gradually, indicating that when the COV is small, the mean value of standard deviation is more sensitive to the COV, and the sensitivity decreases with the gradual increase in the COV. Note that the order of the horizontal fluctuation scale represented in each curve is inconsistent with that shown in the legend, indicating that the mean value of the standard deviation of 


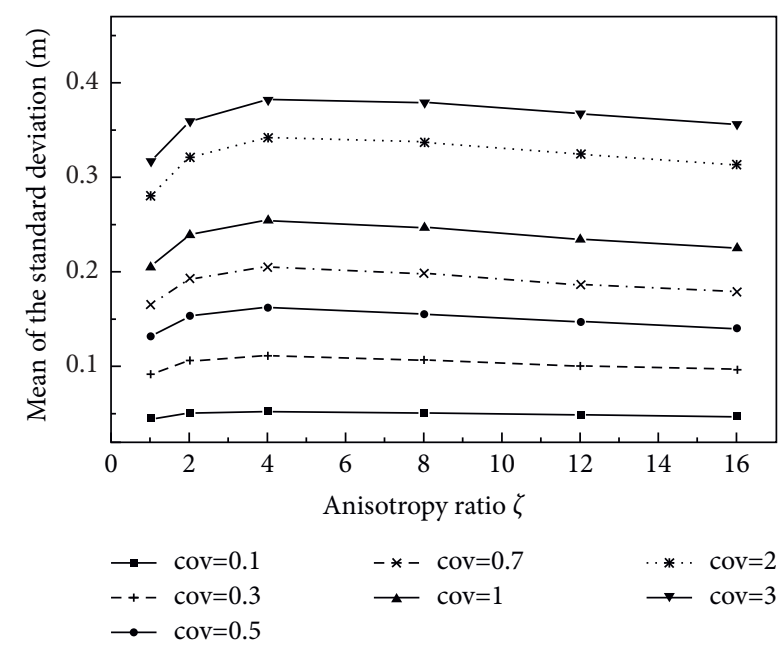

Figure 9: Mean of the total head standard deviation versus anisotropy ratio of hydraulic conductivity.

the total head does not show a consistent law under a specific fluctuation scale.

Figure 9 shows the variation curve of the mean value of the standard deviation of the total head with the anisotropy ratio. The trend of each curve is evident. First, the curves increase and then decrease. The maximum mean value of the standard deviation basically appears at $\zeta=4$. In particular, when $\zeta \leq 4$, the mean value of the standard deviation of the total head increases with the anisotropy ratio. In contrast, for $\zeta>4$, the mean value of head standard deviation decreases with an increase in the anisotropy ratio. Approximate results are mentioned in some research studies [13, 39], but the extreme points are different. Also, literature [17] shows that approximate phenomena can be found in soil by observation.

\section{Conclusion}

In this research, the influence of strong randomness of embankment soil hydraulic conductivity is studied, a threedimensional multimedia permeability random field is generated, and a Monte Carlo process involves 3,000 realizations that are used to solve the three-dimensional random seepage field of the embankment. Based on this study, the following conclusions can be drawn:

(1) Considering the randomness of the hydraulic conductivity, the position of the free surface of each section in the embankment was different.

(2) The maximum standard deviation of the total head appears near the embankment center. When the total head approaches the outer boundary, the standard deviation decreases rapidly. When the COV increases, the mean value of the total head decreases significantly, and the standard deviation of the total head increases significantly.

(3) When the anisotropy ratio was $1 \leq \zeta \leq 4$, the mean value of the total head increases. In contrast, when the anisotropy ratio was $\zeta>4$, the growth rate reduces.
(4) When the COV was small, the fluctuation scale less affected the mean and standard deviation of the water head. In contrast, when the COV increases, the effect of the fluctuation scale increases significantly, and the standard deviation of the total water head increases first and then decreases with the increase in the fluctuation scale.

\section{Data Availability}

The datasets generated during the current study are available from the corresponding author on reasonable request.

\section{Conflicts of Interest}

The authors declare no conflicts of interest.

\section{Acknowledgments}

The authors would like to acknowledge financial support from Key Scientific Research Projects of Colleges and Universities in Henan Province under Grant number (22B570002), Henan College Students' Innovation And Entrepreneurship Training Program under Grant no. (S202110480034), and Key Scientific Research in Xuchang University under Grant number (2021HX157).

\section{References}

[1] J. W. Cooley and J. W. Tukey, "An algorithm for the machine calculation of complex fourier series," Mathematics of Computation, vol. 19, no. 90, pp. 297-301, 1965.

[2] G. Matheron, "The intrinsic random functions and their applications," Advances in Applied Probability, vol. 5, no. 3, pp. 439-468, 1973.

[3] A. Mantoglou and J. L. Wilson, Simulation of Random fields with the Turning Bands Method, Ralph M. Parsons Laboratory Hydrology and Water Resources Systems, Cambridge, MA, USA, 1981.

[4] E. H. Vanmarcke, Random Fields: Analysis and Synthesis, World Scientific, Singapore, 1983.

[5] E. Vanmarcke and M. Grigoriu, "Stochastic finite element analysis of simple beams," Journal of Engineering Mechanics, vol. 109, no. 5, pp. 1203-1214, 1983.

[6] E. H. Vanmarcke and G. A. Fenton, "Conditioned simulation of local fields of earthquake ground motion," Structural Safety, vol. 10, no. 1-3, pp. 247-264, 1991.

[7] G. A. Fenton, Simulation and Analysis of Random fields, Princeton University, New Jersey, NJ, USA, 1990.

[8] G. A. Fenton and E. H. Vanmarcke, "Simulation of random fields via local average subdivision," Journal of Engineering Mechanics, vol. 116, no. 8, pp. 1733-1749, 1990.

[9] G. A. Fenton and D. V. Griffiths, "Random field generation and the local average subdivision method," Probabilistic Methods in Geotechnical Engineering, pp. 201-223, Springer, Berlin, Germany, 2007.

[10] G. A. Fenton and D. V. Griffiths, "The random finite element method (RFEM) in bearing capacity analyses," Probabilistic Methods in Geotechnical Engineering, pp. 295-315, Springer Vienna, Berlin, Germany, 2007.

[11] G. A. Fenton and D. V. Griffiths, "Review of probability theory, random variables, and random fields," Probabilistic 
Methods in Geotechnical Engineering, pp. 1-69, Springer Vienna, Berlin, Germany, 2007.

[12] D. Zhu, D. V. Griffiths, and G. A. Fenton, "Worst-case spatial correlation length in probabilistic slope stability analysis," Géotechnique, vol. 69, no. 1, pp. 85-88, 2019.

[13] G. A. Fenton and D. V. Griffiths, "Statistics of free surface flow through stochastic earth dam," Journal of Geotechnical Engineering, vol. 122, no. 6, pp. 427-436, 1996.

[14] A. A. Ahmed, "Saturated-unsaturated flow through leaky dams," Journal of Geotechnical and Geoenvironmental Engineering, vol. 134, no. 10, pp. 1564-1568, 2008.

[15] A. A. Ahmed and A. S. Bazaraa, "Three-dimensional analysis of seepage below and around hydraulic structures," Journal of Hydrologic Engineering, vol. 14, no. 3, pp. 243-247, 2009.

[16] A. A. Ahmed, "Stochastic analysis of free surface flow through earth dams," Computers and Geotechnics, vol. 36, no. 7, pp. 1186-1190, 2009.

[17] A. A. Ahmed, "Stochastic analysis of seepage under hydraulic structures resting on anisotropic heterogeneous soils," Journal of Geotechnical and Geoenvironmental Engineering, vol. 139, no. 6, pp. 1001-1004, 2013.

[18] C. L. Winter and D. M. Tartakovsky, "Groundwater flow in heterogeneous composite aquifers," Water Resources Research, vol. 38, no. 8, pp. 23-11, 2002.

[19] J. H. He, "Approximate analytical solution for seepage flow with fractional derivatives in porous media," Computer Methods in Applied Mechanics and Engineering, vol. 167, no. 1-2, pp. 57-68, 1998.

[20] C. Chuanmiao and H. Hongling, "Global existence of real roots and random Newton flow algorithm for nonlinear system of equations to memorize Qin's method for 770 anniversaries," Science China Mathematics, vol. 60, no. 7, pp. 1-12, 2017.

[21] L. Smith and R. A. Freeze, "Stochastic analysis of steady state groundwater flow in a bounded domain: 2 . two-dimensional simulations," Water Resources Research, vol. 15, no. 6, pp. 1543-1559, 1979.

[22] B. Yang, D. Li, S. Yuan, and L. Jin, "Role of biochar from corn straw in influencing crack propagation and evaporation in sodic soils," Catena, vol. 204, Article ID 105457, 2021.

[23] B. Yang, J. Liu, X. Zhao, and S. Zheng, "Evaporation and cracked soda soil improved by fly ash from recycled materials," Land Degradation \& Development, vol. 32, no. 9, pp. 2823-2832, 2021.

[24] B. Yang, K. Xu, and Z. Zhang, "Mitigating evaporation and desiccation cracks in soil with the sustainable material biochar," Soil Science Society of America Journal, vol. 84, no. 2, pp. 461-471, 2020.

[25] B. B. Yang, S. Yuan, Y. Liang, and J. Liu, "Investigation of overburden failure characteristics due to combined mining: case study, Henan Province, China," Environmental Earth Sciences, vol. 80, no. 4, p. 143, 2021.

[26] B. Yuan, Z. Li, Z. Zhao, H. Ni, Z. Su, and Z. Li, "Experimental study of displacement field of layered soils surrounding laterally loaded pile based on transparent soil," Journal of Soils and Sediments, vol. 21, no. 9, pp. 3072-3083, 2021.

[27] B. X. Yuan, Z. H. Li, Z. L. Su, Q. Z. Luo, M. J. Chen, and Z. Q. Zhao, "Sensitivity of multistage fill slope based on finite element model," Advances in Civil Engineering, vol. 2021, Article ID 6622936, 13 pages, 2021.

[28] B. Yuan, Z. H. Li, Y. Chen et al., "Mechanical and microstructural properties of recycling granite residual soil reinforced with glass fiber and liquid-modified polyvinyl alcohol polymer - sciencedirect," Chemosphere, vol. 268, Article ID 131652, 2021.

[29] Y. Wu, J. Cui, J. Huang, W. Zhang, N. Yoshimoto, and L. Wen, "Correlation of critical state strength properties with particle shape and surface fractal dimension of clinker ash," International Journal of Geomechanics, vol. 21, no. 6, Article ID 04021071, 2021.

[30] B. Bai, Q. Nie, Y. Zhang, X. Wang, and W. Hu, "Cotransport of heavy metals and $\mathrm{SiO}_{2}$ particles at different temperatures by seepage," Journal of Hydrology, vol. 597, Article ID 125771, 2021.

[31] B. Bai, G.-c. Yang, T. Li, and G.-s. Yang, "A thermodynamic constitutive model with temperature effect based on particle rearrangement for geomaterials," Mechanics of Materials, vol. 139, Article ID 103180, 2019.

[32] R. A. Freeze, "Influence of the unsaturated flow domain on seepage through earth dams," Water Resources Research, vol. 7, no. 4, pp. 929-941, 1971.

[33] R. A. Freeze, "A stochastic-conceptual analysis of one-dimensional groundwater flow in nonuniform homogeneous media," Water Resources Research, vol. 11, no. 5, pp. 725-741, 1975.

[34] R. J. Hoeksema and P. K. Kitanidis, "Analysis of the spatial structure of properties of selected aquifers," Water Resources Research, vol. 21, no. 4, pp. 563-572, 1985.

[35] E. A. Sudicky, "A natural gradient experiment on solute transport in a sand aquifer: spatial variability of hydraulic conductivity and its role in the dispersion process," Water Resources Research, vol. 22, no. 13, pp. 2069-2082, 1986.

[36] H. Huang, B. X. Hu, X. H. Wen, and C. Shirley, "Stochastic inverse mapping of hydraulic conductivity and sorption partitioning coefficient fields conditioning on nonreactive and reactive tracer test data," Water Resources Research, vol. 40, no. 1, pp. 1-16, 2004

[37] D. V. Griffiths and G. A. Fenton, "Seepage beneath water retaining structures founded on spatially random soil," Géotechnique, vol. 43, no. 4, pp. 577-587, 1993.

[38] G. A. Fenton and D. V. Griffiths, "Statistics of block conductivity through a simple bounded stochastic medium," Water Resources Research, vol. 29, no. 6, pp. 1825-1830, 1993.

[39] D. V. Griffiths and G. A. Fenton, "Probabilistic analysis of exit gradients due to steady seepage," Journal of Geotechnical and Geoenvironmental Engineering, vol. 124, no. 9, pp. 789-797, 1998. 